MUZIKOLOŠKI ZBORNIK - MUSICOLOGICAL ANNUAL XI, LJUBLJANA 1975

UDK 781.5 (497.12) Petrić

\title{
PROBLEM FORME V DELIH IVA PETRICA
}

\author{
Andrej Rijavec (Ljubljana)
}

Kadarkoli se v muzikologiji, naj bo to historiografska ali sistematična, skuša preseči nizanje in opisovanje golih dejstev $z$ namenom, da bi se dokopalo do bistvenejših in poglobljenejših spoznanj, se vedno znova pojavi glede znanstvene natančnosti sicer navidez neprijetna, a za vsakršno ustvarjalno delo toliko bolj vabljiva negotovost - relativnost pojmov. Dosegljivost ciljev postane $\mathrm{s}$ tem seveda vprašljiva, nikakor pa ne nemogoča.

Eno izmed takih vprašanj, ki je tudi v naši glasbi kot sestavnemu delu evropske glasbene kulture prostorsko in časovno pogojeno, je vprašanje forme. "Was Form in der Musik ist, steht nicht fest", pravi Carl Dahlhaus, $\mathrm{s}$ čimer kratko in jasno, pa čeprav $\mathrm{z}$ negativnim predznakom, zadeva $\mathrm{v}$ jedro problema. ${ }^{1}$ Ker ni nobenega dvoma o tem, da je možno ločiti med posrečenimi in ponesrečenimi formami, in ker tam, kjer obstoji določena diferenca, mora biti le-ta razložljiva, ${ }^{2}$ bi vprašanje kazalo aplicirati tudi domačih tleh. Da bi se ga lotili z lastno izhodiščno definicijo, se zdi prevzetno, saj bi to bil kaj malo koristen prispevek $\mathrm{k}$ sicer že preštevilnim bolj ali manj uspešnim poizkusom vsebinske določitve tega pojma. Smiselnejše se zdi nakazati glavne tovrstne tendence $v$ novejši teoretični literaturi, pri čemer bo selekcija sama razkrila mnenja, $h$ katerim nagibam, obenem pa značilno osvetlila oblikovni credo obravnavanega skladatelja kot del formalnih in $\mathrm{s}$ tem tudi glasbenih rešitev $\mathrm{v}$ sodobni slovenski glasbi zadnjih dvajsetih let.

Skrajnosti so približno takšne: o kaj takem, kar naj bi bila forma, sploh ni mogoče govoriti, oziroma, vse, kar obstaja, ima tudi formo. Medtem ko prvi zanikajo ne samo vse historične formalne sheme na sploh in jih skušajo nadomestiti $s$ tehnično razčlenljivo strukturo, pa drugi, zlasti Adorno in njegovi miselni nadaljevalci menijo, da vsakršno zvočno dogajanje, ali še natančneje, vsakršni zvočno-časovni nekaj že zavoljo

1 Darmstädter Beiträge zur Neuen Musik X: Form in der Neuen Musik, Mainz 1966, 71.

2 Ib., 72. 
svoje eksistence mora imeti formo. ${ }^{3} \mathrm{Iz}$ obeh, sicer nasprotnih mnenj odseva določena stopnja, ki jo je v svojem povojnem razvoju dosegla evropska glasba in ki je in deloma še vedno odmeva $\mathrm{v}$ jugoslovanskem glasbenem prostoru.

Ne da bi kaj posebno napredovali, že se je pojavil nov pojem, ki ima sam na sebi tudi različne pomene ne glede na vsakdanjo ohlapno rabo: struktura. Čeprav se pojma forma in struktura včasih uporabljata ne samo kot sinonima, ampak bi med njima lahko postavili celo enačaj, kar je zgodovinsko simptomatično, ${ }^{4}$ večina avtorjev med obema postavlja diskrecijski razloček, ki ga koristno in iz različnih zornih kotov pojasnjujejo.

Strukturni problemi so problemi kompozicijske tehnike, ki naj zadevajo predvsem skladatelja samega, medtem ko so za vse ostale dostopne šele na podlagi analize..$^{5} \mathrm{Ne}$ da bi hoteli, kar tudi ne bi bilo smiselno, pojma forme in strukture nasilno ločevati, se zdi, da je struktura marsikdaj modna beseda, ki se tlači - da bi sideološko» rešila formalne probleme - umetno med formo na eni in tradicionalnim pojmom kompozicijskega stavka na drugi strani. ${ }^{6}$ Kaže pa, da je začetke hitrega razcveta pojma struktura iskati $\mathrm{v}$ evropski glasbi petdesetih let in pri zamudnikih deloma še $\mathrm{v}$ šestdesetih, ko je totalna organizacija skrčila vsa kompozicijska sredstva na raven čistega materiala, kar pomeni, da se je moralo $\mathrm{z}$ obnovo forme začeti od začetka. Komponiranje se je sprevrglo $\mathrm{v}$ bolj ali manj intelektualno stopnjevano zlorabljanje materiala, pri čemer se je domnevalo, da bo forma tudi uspešno dosežena, če se bodo vsi strukturni odnosi ujemali: se pravi, da ob forma izključna in neposredna rezultanta čim bolj umetelno strukturiranega materiala. In ravno v tej točki je táko (serialno) oblikovanje zatajilo, namreč na avtomatičnosti rezultata, čeprav ne more biti dvoma, da je forma s strukturo skladbe sicer povezana in sloni na njenem substratu. Tudi nadaljnji potek evropskega razvoja je znan. Totalna determiniranost se je konec šestdesetih let zavoljo informacijske preobteženosti zvočnih izdelkov, kar Pousseur duhovito poimenuje s istrukturalnim molkom", sprevrgla v totalno nedeterminiranost, $\mathbf{s}$ čimer se je problem forme še bolj zaostril, teoretično in praktično. ${ }^{7}$ Polagoma so se oglasili umirjenejši glasovi, ki se morejo uporabiti pri presoji Petrićevih oblikovalnih prizadevanj, saj bi vsakršna drugačna, tradicionalno ali avantgardno nepomirljiva izhodišča izničila skladateljeve formalne rešitve.

Ligeti smatra, da je forma $v$ glasbi več kot nodnos posameznih delov med seboj in le-teh do celote«, v kateri vsaka faza, element, misel, oblikuje

3 Ib., 19, 35; Karkoschka E., Zur musikalischen Form und Formanalyse, Probleme des musiktheoretischen Unterrichts, Berlin 1967, 40.

4 Gieseler W., Komposition im 20. Jahrhundert, Celle 1975, 77; Supičić I., Matter and Form in Music, The International Review of Music Aesthetics and Sociology, Vol I, No. 2, 1970, 149 sl.

5 Gieseler W., ib.

6 Darmstädter Beiträge, ib., 72-3.

7 Gieseler W., ib., 133-4; Kelterborn R., Die Problematik der Formbegriffe in der Neuen Musik, Terminologie der Neuen Musik, Berlin 1965, 48 sl.; Spink I., A Historical Approach to Musical Form, London 1967, 214; RILM, IV/2, 1970, 2557. 
zveze oziroma ne-zveze, torej sistem odnosov, ki ustvarjajo videz gibanja oziroma mirovanja. Čeprav temu problemu ne najde pozitivne rešitve, razvije za vsakršno analizo nujno misel, da je forma pravzaprav abstrakcija časovnega glasbenega procesa, se pravi, da jo lahko fisiramo šele, ko se glasbeno dogajanje retrospektivno pregleda kot prostor. ${ }^{8}$ Karkoschka gre glede na doslej povedano koristno naprej, ko ugotavlja, da je s stališča dojemanja struktura omejena na vsakokratni "sedaj", forma pa na celoto, ${ }^{9}$ ali nekoliko po svoje in še dljé Dahlhaus, ko pravi, da je struktura neke kompozicije tisti aspekt, ki zanima predvsem skladatelja, forma pa poslušalca. ${ }^{10}$ Erpf zaobrne odnos med formo in strukturo zopet nekoliko drugače: "Forma v glasbi je slišno doživetje neke strukturte»,"11 kar pomeni, da se more realizirati samo v poslušajočem subjektu; oziroma, da obstoje zvočne strukture (ob vsakokratnem "sedaji), ki jih, kar je statistično dokazano, ali sploh ni mogoče slišati in torej glede na nakazana izhodišča ne morejo vplivati na zvočno formo,12 in take, ki ob študiju in analizi partiture ter po večkratnem poslušanju ene in iste skladbe morejo prodreti $\mathrm{v}$ slušno zaznavno polje in postati sonosilke forme. Obe stališči je možno izpodbijati iz dveh zornih kotov, ki pa so večinoma že izven Petrićevega načina oblikovanja: prvo stališče je za vse tiste, ki smatrajo, da je strukturna (pa čeprav neslišna) kompliciranost fakture porok in merilo kvalitete, nesprejemljivo, saj $\mathrm{v}$ glasbeno doživljanje - kar nikakor ni prvič v zgodovini - vključujejo tudi vizualno oziroma intelektualno obravnavanje partiture; drugo je zlasti napoti tistim gledanjem, ki v vse večjo svobodo zvočnega dogajanja vključujejo izvajalce in poslušalce kot bistvene sooblikovalce forme. Pa vendar se zdi drugo, prej omenjeno stališče, sprejemljivo, saj velja za ogromno večino glasbe, ki je predvsem zvočna umetnost in, pri Petriću izključno zvočna umetnost. Ob tem stališcu se namreč izčisti vsa relativnost pojmov tako strukture kot forme kot tudi njunega medsebojnega odnosa: forma se kljub osnovni danosti nekako "napaja» iz podrejene ji strukture; če je ta sicer objektivno oziroma teoretično $\mathrm{v}$ končni konsekvenci samo enovrstno razložljiva, pa postane zavoljo problemov različne percepcije variábla, ki ustrezno vpliva na formo in slednji ne dopušča značaja konstante. Ker je, kot rečeno, Petrićeva glasba izključno zvočna umetnost, ki torej ne operira $s$ kakšnimi vizualnimi oziroma intelektualnimi dodatki in $\mathrm{v}$ kateri skuša komponist doseči slušno dojemljiv vtis, ${ }^{13}$ pridejo $\mathrm{v}$ zvezi $\mathrm{z}$ obravnavano temo še najbolj v poštev tiste definicije, ki pravijo, da je forma neke skladbe celovitost tonskih odnosov, ki jih zaznamo ob poslušanju. ${ }^{14}$

Ali bo uspešna ali ne, je seveda drugo vprašanje, ker se tukaj pojavi problem smiselnosti oziroma estetske sprejemljivosti doseženega ravnotežja med posameznimi členi in celoto, med determiniranim in nedeter-

\footnotetext{
8 Darmstädter Beiträge, ib., 23.

9 Karkoschka E., ib., 49.

10 Darmstädter Beiträge, ib., 73.

11 Erpf H., Form und Struktur in der Musik, Mainz 1967, 168.

12 Versuche musikalischer Analysen, Berlin 1967, 60.

13 Blume J., Komposition nach der Stilwende, Wolfenbüttel \& Zürich 1972, 10.

14 Prim. Erpf H., ib., 213; Zeitschrift für Musiktheorie, Jg. 1, 1970/1, 39.
} 
miniranim, ali, v bolj sodobni govorici, ravnotežja med parametri, ki pa pri Petriću ne pridejo $\mathrm{v}$ poštev, saj $\mathrm{s}$ temi novodobnimi in vse prevečkrat malikovalsko izrabljanimi pojmi ne operira. Pač pa se zaveda, da je forma pravzaprav sintelektualna korekcija intuitivno dosežene" oziroma sintuitivna korekcija intelektualno postavljene» zasnove. ${ }^{15} \mathrm{Iz}$ obeh različic izhaja, da uspešna forma ni rezultat znanja, to je poznavanja in uporabe takšnih ali drugačnih kalupov, ampak posledica ustvarjalnim osebnostim lastnega občutka za obliko; se pravi: občutek za formo, ki je edini odgovoren za njeno uspešnost, je ustvarjalni kompromis med intuicijo in intelektom, kompromis, v okviru katerega je nešteto rešitev, ne da bi se pola izključevala.

Ker je govor o občutkih (za formo), ki jih ni mogoče "dokazati«, se zdi na tem mestu edino možno nanizati Petrićeve formalne rešitve $\mathrm{v}$ posameznih fazah skladateljevega razvoja in ugotoviti njihove skupnosti in različnosti oziroma bistvene značilnosti. Ker gre pri tem obenem ne samo za karakteristična dela, ampak za skoraj izključno taka, ki so bila večkrat in deloma celo neštetokrat uspešno avditivno percepcirana, je nujno, da so tudi formalno posrečena.

Skladateljevo neoklasicistično oziroma neobaročno fazo, ko je bil v petdesetih letih še študent in ki traja do začetka šestdesetih let, ko se je stilno preusmeril, naj s stališča forme osvetlijo štiri kompozicije: Sonata za fagot in klavir (1954), Sonata za klarinet in klavir (1957), in na orkestralni ravni Concerto grosso za godala (1955) ter III. simfonija (1957). Sonata za fagot je podobno kot Sonata za klarinet samo ena izmed vrste komornih sonat in koncertov, ki jih je po vzoru klasikov 20. stoletja, kot so Bartók, Prokofjev, Šostakovič, Honegger in predvsem Hindemith, napisal v smislu muzikantskega vodila "glasbe za uporabo in igranje" (Gebrauchs- \& Spielmusik). To dejstvo velja zapisati že na samem začetku, ker se bolj ali manj vleče skozi celoten Petrićev opus in ker bistveno zadeva njegovo tretiranje fortme, ki tudi poslej ne bo - razen dveh ali treh informativnih oziroma eksperimentalnih poizkusov - mogla zaiti $\mathrm{v}$ razne serialne in podobne kasnejše strukturalne različice oblikovanja. Obe omenjeni sonati sledita $\mathrm{v}$ osnovi neobaročnim oblikam. ${ }^{16}$ Tovrstna vzorovanja. odsevajo na različnih ravneh: v občasni monotematičnosti, ki nima za po. sledico samo nadaljnjega spletanja (Fortspinnung) zvočnega tkiva, ampak se slednji princip razširi tudi na področje forme. Tako je možno 3. stavek Sonate za fagot formulirtati kot a b $a_{1} b_{1} \quad c \quad a_{2} b_{2} \quad c_{1}$, 1 . stavek Sonate za klarinet pa kot $a b \quad x \quad a_{1} b_{1} \quad$ y $a_{2} b_{2}$. V obeh primerih imamo opraviti z ronđojsko-variacijskimi prijemi, ali bolj splošno, $\mathrm{z}$ nizanjem, razvijanjem, kontrastiranjem in uravnovešenjem, ko skladatelj zaključi $z$ znanim, ne da bi se vrnil na izhodišče. Podobno formo, a v večjem obsegu, ima tudi 2., obenem zadnji stavek Sonate za klarinet in klavir, ki predstavlja kontrastno združitev drugega in tretjega stavka sicer zavestno nerealizirane trostavčnosti. Uravnovešenje je ponekod bolj tradicionalno,

$15 \mathrm{Iz}$ osebnega razgovora s skladateljem pozimi 1974/75.

16 Borris S., Probleme der Sonatenform im 20. Jahrhundert, Musik im Unterricht $\mathrm{A} / \mathrm{LIX} / 11,1968,371$ sl. 
ko se skladatelj posluži tro- ali večdelne formalne simetrije. Še veliko več simetričnih prijemov odseva Concerto grosso, saj so na podlagi trodelnosti zgrajeni kar trije stavki: zaključni Vivo, tretji Largo in uvodni trodelni Grave-Lento-Grave, v katerem so mejni deli, tudi trodelni. 2. stavek, Allegro, je zopet značilen. Kaže namreč na odpor mladega skladatelja, da bi - če že sprejema nekatere formalne stalnice uspešnega oblikovanja prevzemal tudi klasične oblike; zato fugo zavoljo kontrastnih misli svobodno povezuje $\mathbf{s}$ sonato. Če se zdi slednja rešitev še nekoliko elektična, kaže 1. stavek trostavčne III. simfonije naprej: jasna, kontrastna dvotematičnost, ki jo uspešno izrabi za stopnjevanje $\mathrm{k}$ dvem izrazitim viškom, in trodelnost, ki bi jo mogli sonatno zagovarjati, se razblinita, ko ta sonatnost ne vključi tudi vrnitve na izhodišče. Vsaj $v$ tem trenutku ne, vse dokler, po značilnem, schrezoznem a $\mathrm{b} \mathrm{a}_{1} \mathrm{c} \mathrm{a}_{2}$ srednjem stavku, skladatelj makroforme ne zaključi tako, da se kar ponuja nekoliko poenostavljena formula III. simfonije, namreč A B $A_{1}$. Če že torej simetrija, potem na vsak način variirana, komprimirana ter intelektualno oziroma intuitivno, se pravi ustvarjalno korigirana.

Nova zvočnost, v začetku še neznanka, ki jo je skladateljeva generacija šele slutila, je ob prelomu v novo desetletje tudi v domačem okviru dobila veljavo. Obiski avantgardnih centrov in festivaìov, zlasti Varšavske jeseni, organiziranje podobnih prireditev $\mathrm{v}$ domovini, zlasti Zagrebškega biennala, ustanovitev ansambla Slavko Osterc, so opravili svoje: mrzlično in z na. vdušenjem se je tudi Petrić vrgel v raziskovanje novih zvočnih možnosti, $\mathrm{v}$ eksperimentiranje $\mathrm{z}$ raznimi kombinacijami instrumentov, $\mathrm{v}$ širjenje načinov vzbujanja zvoka, $\mathrm{v}$ iskanje novih zvočnih barv, $\mathrm{v}$ uvajanje in izrabljanje aleatorične, pa vendar kontrolirane nedeterminiranosti in podobno. Ker med tem ni bil doživel "totalitarne« faze komponiranja, načina, ki se mu je izognil že zavoljo drugače usmerjenih dispozicij, je razumljivo, da na oblikovni ravni sedaj ni zašel v katerokoli od različic odprtih form. Kljub temu postane odmik od klasičnih oblik, kolikor jih je sploh, pa še prilagojene, uporabljal, še bolj zavesten. In obenem nujen: samo izjemoma tematski, večinoma pa netematski način oblikovanja zvoka zahteva bolj svobodne, drugačne in vsakokrat nove formalne rešitve. In vendar: tudi $\mathrm{v}$ teh formah kljub novim prijemom določeni starejši oblikovalni principi ne zataje.

Ker je skladateljevo zanimanje $\mathrm{v}$ začetku usmerjeno predvsem $\mathrm{v}$ obvladovanje novih zvočnih možnosti, je forma pravzaprav v drugem planu; a zanimivo: njena uresničitev je sedaj rezultat instrumentacijske zasnove, z drugimi besedami, zasedba postane osrednji element oblikovanja. Prva taka skladba je Croquis sonores (1963), v kateri so $\mathrm{v}$ petih stavkih instrumenti komornega ansambla takole razvrščeni: I. - harfa solo, II. - harfa \& tolkala, III. - harfa, oboa, basklarinet, rog, kontrabas, IV. - baskla rinet, kontrabas, tolkala, klavir, V. - tutti. V tej smeri so Simfonične mutacije (1964) bolj zanimive. Sestoje iz petih stavkov: Torso - Largo, Agitato, Lento, Giocoso, Conclusione - Largo-Animato-Poco moderato-Improvisato-Stretta. V Torsu skladatelj $\mathrm{v}$ temačnem in statičnem vzdušju predstavi praktično vse instrumente, vendar se formalno nič ne "zgodi«; 
to je začetek, za katerim so vse možnosti odprte, tako da osrednji trije, po svoji zasedbi in medseboj kontrastnem značaju različni stavki lahko pripravijo zaključno zvočno kataklizmo. Tako se petstavčnost kompozicije sprevrže $\mathrm{v}$ trodelnost I II\&III\&IV V, ki pa, kar je pri Petriću izjemno, ne pomeni uravnovešeno pomirjujoče simetrije, ampak oblikovni crescendo, ki ga je možno ponazoriti s stopnjevanjem: pozitiv - komparativ - superlativ.

Če Mozaiki za klarinet in komorni ansambel (1964) še sledijo isti formalni logiki, pomeni Epitaf za klarinet, harfo, violino, čelo s tolkali in godalnim orkestrom (1965) korak naprej. Na eni strani se Petrić rešuje šablonstva kombinacij zasedb, na drugi pa zapusti svoj (hindemithovsko podedovani) pihalni zvok $\mathrm{z}$ vse večjo uporabo godal. Ker $\mathrm{s}$ tem zajadra $\mathrm{v}$ večjo senzibilnost, ki mu presenetljivo bolj ustreza, kot to dokazuje vrsta uspelih kompozicij $\mathrm{v}$ zadnjem desetletju, se strukturna raznovrstnost materiala poveča. Nove možnosti redčenja in zgoščevanja zvoka, kontrastov $\mathrm{v}$ barvah in vzdušjih, $\mathrm{v}$ poglobljeno izraznem in $\mathrm{v}$ molku, $\mathrm{v}$ tematskem in netematskem, fiksiranem in nefiksiranem, obogatijo strukturo, kar mora nujno odmevati tudi na formalni ravni: manj je ponavljanja in simetrije, zato pa več psihološko utemeljenejšega spreminjanja. Pa vsemu navkljub: stari oblikovani principi se bodo še pojavljali in obrisi forme bodo še nadalje jasni, čeprav literarno včasih težje razpoložljivi. Razen redkih oblikovnih izjem $\mathrm{v}$ smislu uiz teme $\mathrm{v}$ zmagou izpričuje večina kompozicij poslej obliko loka, $\mathrm{v}$ velikem in $\mathrm{v}$ malem.

$\mathrm{V}$ letu 1968 izstopata dve skladbi: Intarzije za pihalni trio in komorni ansambel in Integrali $\mathrm{v}$ barvi, zvočna (simfonična) razmišljanja ob Kosovelovi poeziji. Za Epitaf je možno trditi, da je introvertiran, medtem ko obe omenjeni skladbi izkazujeta neoimpresionistične barvne kvalitete, kar pa je $\mathrm{v}$ tem trenutku bolj postranskega pomena. Intarzije sledijo znanim, starejšim in novejšim formalnim prijemom, pri katerih se princip zasedbe povezuje $\mathbf{s}$ principom mikro- in makro-lokov, ki usahnejo $\mathrm{v}$ nič, medtem ko je formalna petdelnost poudarjena $\mathrm{z}$ naslednjo instrumentacijsko shemo: Prologo - tutti, Canto I - klarinet, Canto II - fagot, Canto III - flavta, Epilogo - tutti. Oboji principi odsevajo tudi v Integralih: bodi $\mathrm{v}$ osnovnem loku, ki vsebinsko vodi iz vedrega do kulminacije $\mathrm{v}$ resignacijo, bodi $\mathrm{v}$ tutti in vse intenzivnejši aleatorični zasnovi osrednjega četrtega stavka, bodi v simetriji posameznih stavkov, ki jo zlasti izkazuje tretji, v tem primeru petdelni stavek. Tudi Burlesque pour les temps passés, duhovito in igrivo delce iz leta 1969, vsebuje podobne kombinacije osnovnega, na sredi kulminirajočega loka, z "zmagovito" kodo, in na bistveno zreducirane simetričnosti: trodelnost - kadenca - godala - kadenca - trodelnost.

Približno v tem času, $\mathrm{v}$ fazi vse bolj poglobljenega obvladovanja novega zvoka, se Petrić na komornem in orkestralnem področju usmeri $\mathrm{h}$ klasičnim zasedbam, in sicer takim, ki jih je nekoč, v drugačni govorici že preizkusil, a se jih doslej, v novem jeziku še ni upal lotiti. Najprej je tu Quatuor 1969 za godalni kvartet, $\mathrm{v}$ katerem se ob formalnem decrescendu v prvem stavku in formalnem crescendu $\mathrm{v}$ drugem stavku, mutatis mutandis, 
po dolgem času uveljavi tudi tematična enovitost skladbe. ${ }^{17}$ Podobne formalne rešitve si sledijo tudi na orkestralnem področju: v Musique concertante za klavir in orkester (1970), v kateri je sicer razgibani formalni lok prvega stavka možno povezati z oblikovnim crescendom drugega, pa v Dialogues concertants za čelo in orkester (1972), ali v Trois Images za violino in orkester (1973), $\mathrm{v}$ katerih sta obe kulminaciji $\mathrm{v}$ prvem stavku samo pripravi za še močnejši in osrednji višek $\mathrm{v}$ srednjem stavku, kar lahko pomiri in uravnovesi samo "neskončno», skoraj romanitično usihanje v tretjem, ali, nikakor ne nazadnje, v Fresque symphonique (1973), ki je v svojem bistvu "dvotematična» skladba v obliki značilnega Petrićevega loka z dvema izraznima in formalno zaznavnima vrhovoma.

Kakor pravkar omenjena dvotematičnost kaže nazaj, je podobne tendence zaslediti tudi na komornem področju. Če so Meditacije za violino, violončelo in klavir (1971) po fakturi blizu Quatuor 1969, pa glede forme sledijo starejšim vzorom izpred desetih let, ko je bila zasedba osnovni formativni dejavnik. $\mathrm{V}$ smislu retrospektivnosti se zdita zanimivi še dve kompoziciji: Gemini Music za celo in klavir (1971) in Les paysages za klavir (1972). Prva predstavlja efektni, virtuozno in improvizacijsko zasnovani duo, ki je tudi formalno karakterističen. Na prvi pogled vzbudi vtis nizanja vedno novih misli. A ni tako. Pozornejši vpogled pripelje do spoznanja, da se kljub neštetim delom in delčkom, ki bi $\mathrm{v}$ oblikovni formuli zahtevali skoraj polovico abecede, določena glasbena misel, pa naj je še tako transformirana, občasno pojavlja in $\mathrm{s}$ tem prevzema vlogo oblikovnega nosilca. Torej: a $\ldots \ldots a_{1} \ldots \ldots a_{2}$. Rondo? Odgovor bi moral biti pritrdilen. Les Paysages, $v$ nadaljevanju naslova Esquisses poetiques pour piano, so še zanimivejše. Skladba ima pet stavkov, ki nosijo posamezne programske naslove: Les paysages de chaque jour, Les couleurs du paysage, Les Métamorphoses du paysage, Le paysage vide, Le paysage de la vie. Klavirsko-tehnično in izrazno kontrastni stavki predstavljajo stopnje v razvoju zvoka in forme; $\mathrm{z}$ besedami morda takole: $\mathrm{v}$ prvem stavku skladatelj zastavi zvok, v drugem ga bogati, $v$ tretjem razgiba, v četrtem ustvari predah, da bi z množico različnih zvokov sklenil finale, ki pa je sam na sebi sinteza novega in "mezza voce» reminiscenc prejšnjega:

$\begin{array}{llrrc}\text { I } & \text { II } & \text { III } & \text { IV } & \text { V } \\ \mathrm{a} & \mathrm{b} & \mathrm{c} & \mathrm{d} & \text { e }\left(\mathrm{a}_{1}\right) \mathrm{e}_{1}\left(\mathrm{~b}_{1}\right) \mathrm{e}_{2}\left(\mathrm{c}_{1}\right) \mathrm{e}_{3}\left(\mathrm{~d}_{1}\right) \mathbf{e}_{4}\end{array}$

$\mathrm{Na}$ dlani je dejstvo, da imamo opraviti z različico nekakšnega variacijskega rondoja, forme, ki jo je Petrić že nekoč uporabljal in katere principi nizanja in variiranja so karakteristični za ves njegov opus. Konec koncev, ponovitev zahteva kontrast in kontrast ponovitev. Ker pa se oboje lahko sprevrže v monotonijo, so potrebne variante obeh.

Domnevno vsa glasbena ustvarjalnost uporablja podobne oblikovalne postopke: nizanje, razvijanje in uravnovešenje. ${ }^{18} \mathrm{~S}$ tega stališča Petrić ni 97-102

17 Rijavec A., Novejši slovenski godalni kvartet, Muzikološki zbornik IX/1973,

18 RILM, II/2, 1968, 2667. 
odkril ničesar novega, a kaže, da se teh aksiomskih resnic zaveda in jim s pridom sledi, ker bi sicer njegove kompozicijske stvaritve zavoljo pomanjkljivosti forme ne bile uspešne.

\section{SUMMARY}

The article discusses the problem of form in the work of the contemporary Slovene composer Ivo Petrić. After a brief presentation of the latest divergent principles as regards this theoretical question, specifically, what form is, what it can be, or rather what it should be, as well as what is its relation to its subordinate structure, the following conclusion is arrived at: in spite of having a kind of given existence, form in a way feeds on the structure; the latter, though theoretically in the last instance unambiguously explicable, becomes owing to differences in perception a variable thus influencing the form and depriving it of becoming a constant. It is from such points of departure that the composer's formal procedures are presented. The analysis reveals that in all the phases of the composer's development, irrespective of his momentary stylistic orientation and irrespective of even most modern sound, Petrić - thanks to an inherent creative sense of form - operates with form-building procedures which seem to be typical of all musical cultures: a balanced treatment of repetition, variation and contrast makes unity - and form. 